\title{
CONSOLIDACIÓN DE UN ESTADO NACIÓN EN NOTICIA DE UN SECUESTRO (1996), MEDIANTE UNA POLÍTICA CRIMINOLÓGICA ${ }^{1}$
}

\author{
Consolidation of a nation State in News of a Kidnapping (1996), through a criminological policy \\ Jesús Miguel Delgado Del Aguila \\ Universidad Nacional Mayor de San Marcos, Lima, Perú \\ tarmangani2088@outlook.com
}

\begin{abstract}
Resumen
Para el desarrollo de este estudio, tomo en cuenta la novela periodística de Gabriel García Márquez, titulada Noticia de un secuestro (1996), la misma que sirve como referente para abordar una etapa crítica por la que atravesaba Colombia durante los dos últimos decenios del siglo XX. Este lapso se caracterizó por la presencia de corrupción gubernamental, el tráfico de drogas y la lucha armada. Ante esta situación social y política, se plantea como solución legal la incorporación de una política criminológica, la cual es posible transferir en dos áreas específicas: las entidades del orden y los miembros de grupos narcoterroristas. En este proceso de menoscabar las deficiencias que provocan el Estado y sus opositores, los textos $\mathrm{La}$ arqueología del saber, Microfísica del poder y Vigilar y castigar de Michel Foucault son de utilidad por postular una nueva modalidad de afrontar la forma de sancionar a un reo, basada en la disciplina y proyectada hacia su reinserción eficaz en la sociedad.
\end{abstract}

Palabras claves: Michel Foucault, disciplina, prisión, formas del orden, Estado nación.

\begin{abstract}
For the development of this study, I take into account the journalistic novel by Gabriel García Márquez, entitled News of a Kidnapping (1996), the same one that serves as a reference to address a critical period that Colombia was going through during the last two decades of the century XX. This period was characterized by the presence of government corruption, drug trafficking and armed struggle. Faced with this social and political situation, the legal solution includes the incorporation of a criminological policy, which can be transferred in two specific areas: law enforcement agencies and members of narco-terrorist groups. In this process of diminishing the deficiencies caused by the State and its opponents, the texts The Archeology of Knowledge, Microfisics of Power and Vigilance and Punish by Michel Foucault are useful for postulating a new way of dealing with the way to punish an inmate, based on discipline and projected towards its effective reintegration into society.
\end{abstract}

Keywords: Michel Foucault, discipline, prison, forms of order, nation State.

Fecha de Recepción: 26/11/2018 - Fecha de Aceptación: 30/12/2018

\footnotetext{
${ }^{1}$ El presente texto forma parte de la tesis inédita del autor "Ausencia de un Estado nación en Noticia de un secuestro (1996), a partir de un período de macrocriminalidad (últimos dos decenios del siglo XX en Colombia)", correspondiente al Grado de Maestría.
} 
Para que la literatura como disciplina consiga una proliferación académica, es necesario que establezca los parámetros que le resultan útiles para conformar un paradigma que le posibilite encontrarse con otras áreas temáticas, como las relacionadas con la filosofía o la sociología; en ese sentido, un objeto de estudio literario es colocado en una intersección conveniente para que se desarrolle una investigación respaldada en un proyecto más profundo, con la asimilación de categorías extratextuales que se vinculan con la significación implícita del discurso narrativo. Esta premisa es fundamental para aludir a la novela periodística Noticia de un secuestro (1996), que posee referencias heterogéneas de historia, geografía, política, sociología, entre otras disciplinas; por esa razón, su tratamiento exclusivamente literario y organizativo es intransferible si no se sabe la acepción de los componentes que constituyen la historia de este libro. Por lo tanto, retomo términos de las áreas de la criminología y el derecho para proponer una solución a las luchas internas que se exhiben en la narración: la oportunidad de menoscabar los elementos que producen la desaparición del Estado nación en una etapa macrocriminal entre los años 1980 y 2000. Bajo esta configuración, encuentra la concepción de política criminológica, distinguida por las categorías de prevención y resocialización (Norza, González Rojas, Moscoso y González Ramírez 2012), que originan una fundamentación lógica de acuerdo con la participación confusa de las entidades militares, debido a su proceder y su forma de ejercer el castigo (abarcada por Foucault).

\section{La articulación de una política criminológica}

Este término es explicado por Rodríguez Manzanera (1981) como aquella disputa ejercida cautelosamente en ocasiones en que la justicia se muestra de modo desfavorable. Por ejemplo, su intervención es propicia cuando funcionarios públicos laboran con personas respaldadas ilegal o delictivamente; ante ello, se producen situaciones de corrupción o amenazas que tendrían que ser contrarrestadas. Para que este proceder sea efectivo, se necesita una reformulación de decretos y planes de gobierno que regule y filtre las conductas negativas que poseen determinados individuos. En ese sentido, el conocimiento de la criminología en los allegados permitirá que se incentiven mejores estrategias jurídicas de reducción criminal.

Para Rodríguez Manzanera (1981 120), la composición del Derecho Penal no es dinámica en muchos países, ya que, de estar alterándose constantemente, irrumpiría con la estabilidad que caracteriza a toda ley, además de que es imprescindible conservar la protección de los bienes jurídicos y percatarse de las exigencias que van requiriendo los ciudadanos a medida que transcurre el tiempo. 
En consecuencia, los países latinoamericanos de ese período contaron con ese percance basado en la regulación defectuosa de su economía y su cultura; mayormente, en localidades paupérrimas. Por esta razón, el crimen y el entorpecimiento de proyectos trascendentales para una comunidad resultan validados. La descripción que realiza el autor de Noticia de un secuestro (1996) sobre los miembros del Estado y el poder judicial es debatible, puesto que posibilita observar las condiciones deplorables por las cuales pasa un gobierno que no ha sido configurado utópicamente bajo la aceptación de una ciudadanía democrática, a causa de que no prevalece una consolidación de principios e infracciones específicas resguardadas por policías; por lo tanto, la corrupción surge de allí como una modalidad de negociación que está exponiendo la deficiencia administrativa por la que está atravesando el país:

Colombia no había sido consciente de su importancia en el tráfico mundial de drogas mientras los narcos no irrumpieron en la alta política del país por la puerta de atrás, primero con su creciente poder de corrupción y soborno, y después con aspiraciones propias (García Márquez 1996 29).

Básicamente, la política criminal es abarcada desde la prevención y la resocialización (Norza, González Rojas, Moscoso y González Ramírez 2012 353-354). Con estos postulados y retomando la novela de Gabriel García Márquez, el establecimiento de un Estado nación acaba siendo conveniente en Colombia.

El primer término consiste en la prevención, que es de utilidad desde su abordaje político, ya que busca menoscabar la frecuencia de la acción criminal. Por una parte, se detecta la facultad correctiva del Estado, mediante intervención policial, y, por otra, se halla el accionar que se deriva de no motivar la ejecución de infracciones, por penas impuestas. Considerando la política criminal, se pretende proponer de manera externa los mecanismos que evitan la transgresión de la ley, que incorporan igualmente estrategias que contrarrestan los factores de riesgo. Frecuentemente, el combate contra la droga promueve otras formas de delinquir, como la represión social de agentes policiales y la modificación de la organización de la sociedad, tal como las argumenta Michel Foucault (1979b 38).

El segundo término es la resocialización, que se vale de la conformación de aquello que delimita la libertad del reo; previamente, contando con la inspección de su operatividad. Sobre ello, principalmente, se formula erigir un sistema de estructuración disímil, sin irrumpir la justicia, con un tratamiento que respalde los rasgos elementales de los ciudadanos, como su género, su profesión, su árbol genealógico, etc. Encima, con el propósito de realizar un enfoque más eficaz de la resocialización, se arguye la distinción de una colectividad en específico, mediante las causas que provocaron el emprendimiento de la transgresión (Norza, González Rojas, Moscoso y González Ramírez 2012 354). Simultáneamente, se tiene la expectativa de incentivar la no 
frecuencia de un mal hábito o un delito por parte del reo hasta que salga en libertad. Si en el país se restringen los derechos básicos, destaca un requerimiento de resocialización para los presos (como la configuración utópica de una sociedad que se rige desde un Estado nación), por la manifestación macrocriminal. Esta empezaría a caracterizarse al observarse la diferenciación colectiva de los actos criminales, prescindiendo de un fundamento legal basado en la democracia.

En función de estos conceptos, planteo la inserción de políticas criminológicas, retomando los paradigmas de prevención y resocialización. Uno de ellos se compone de la adquisición de una jerarquía imperante; el segundo se desarrolla por la inclusión de la igualdad ciudadana para un distanciamiento de vivencias macrocriminales; el tercero se reconoce por la constitución de una política que sugiere el dominio de una técnica para la propagación de la educación, las artes y la cultura; el cuarto se fija en la secuencialidad y el mejoramiento de principios que resguardan la protección ciudadana; el quinto consiste en la instrucción especializada en torno al Derecho.

1. Asimilación de una jerarquía imperante y dominadora. Carlos Aguirre (Szurmuk y Mckee 2009 124) comprende por hegemonía un modo de ejercer el avasallamiento, que se elaborará por la permanencia de la violencia, porque esta resultará indispensable para ejecutar variedades de afrontar el poder. Debido a esas confrontaciones heterogéneas (con sus efectos particulares, autorizados por un poder), la verdad se originará, y será correlativa con la postura que tenga cada persona sobre ella. Por tal motivo, prevalece una politización, que se cerciora en la banalización que surge de esta categoría para alejar a los expertos de la materia y acercar a quienes están más asociados con la cultura popular masiva, con el fin de defender un dogma no muy bien sustentado. Ese poder será ideológico si únicamente se adopta un prototipo de intervención política, ya que se refiere, considerando una ideología organizadora, a una consecuencia de que remotamente existió una inestabilidad, debido a un conflicto, y que hubo estrategias para canalizarla. María García (Szurmuk y Mckee 2009 211-212) argumenta que el poder se evidencia en la sociedad, además de localizarse en disputa y modificaciones constantes; asimismo, es notorio en las conductas de las personas y lo que ellas provocan. Adicionalmente, por tratarse de un vínculo de fuerza, depende de un permanente desajuste que genera una reforma en la sociedad por conflicto de contrarios: la práctica del poder en oposición a las maneras heterogéneas de no adquirirlo. No obstante, al constituir y adaptar esa ideología masiva, se erige una política cultural, como lo asevera George Yúdice (Szurmuk y Mckee 2009 214), que es correlativa con los propósitos del Estado, como cuando se respalda la conservación de la ciudadanía, mediante la planificación de proyectos peculiares, que producen mejorías en el campo económico y laboral. 
2. Inclusión de la igualdad ciudadana para un distanciamiento de las vivencias macrocriminales. Para resolver esta situación, se prefiere encontrar el método exclusivo para suscitar la separación con lo macrocriminal, sin que sea destacable que la sociedad esté relacionada con una manipulación, puesto que, al patentizar una escisión cultural entre los ciudadanos, se priorizan soluciones disímiles y hasta, en algunas ocasiones, inversas a otras ya mostradas; por consiguiente, se debe reorientar el objetivo principal. La atribución adecuada resulta ser la exploración por alcanzar la igualdad o la exposición autónoma de la sociedad. Existe un requerimiento de exhibir un efecto organizado para todas las sociedades, que prevalezca un perfil independiente y profesional, sin obstáculos para que uno tome decisiones políticas y reconozca la veracidad a través de documentación que se halla al alcance de la ciudadanía, porque también es un derecho de las personas asimilarla, tal como lo indica Calvo (2006 118). Al respecto, el liberalismo y el comunitarismo son dos líneas de pensamiento que autorizan la pervivencia de sectores reducidos y la conservación de derechos mayoritarios; ya que, por medio de estas, se logra el respaldo de los principios fundamentales de la sociedad. Un Estado detallado por esa doctrina posee el deber de asegurar sus valores esenciales, con el fin de que se desenvuelva de modo individual. Por ello, tendría que ser homogéneo y afrontar las múltiples representaciones de las personas, según su naturaleza política, religiosa, racial u otro rasgo, sin predominar ni desmotivar una en concreto. Aquello posibilita que algunas minorías se mantengan y se manifiesten con independencia. Aparte, retomando lo propuesto por Raúl Carnevali (2007 11-12), no se identifican esos grupos menores, debido a que, si se realiza, se niega la autorización legalizada de su producción; pues, al ser paradigmática su exteriorización, conllevará la propensión de una colectividad implicada a futuro.

3. Conformación de una política estratégica. Según Theodore Roszak (1981 19), la solución se presenta desde la concepción de tecnocracia, ya que el Gobierno usa mecanismos institucionales pertinentes, para determinar la conducta de personas expuestas de formas individual o colectiva. Encima, la eficacia será apreciada al considerarse a la sociedad como aquella entidad que está en condiciones aptas para que se ejecuten en ella programas modernizadores e industriales. A causa de una organización utópica, se evidencian mejores resultados: protección y organización ciudadanas eficientes. De manera equivalente, un postulado afín se asocia con la beneficiosa propagación de las artes y la educación; aunque, para que se cumpla, se percibe un percance persistente: deficiencias con la inversión monetaria, porque estos proyectos culturales infalibles necesitan una economía exorbitante. 
4. Secuencialidad y mejoramiento de principios que resguarden la protección ciudadana. Los delitos se originan por la exhibición de un capitalismo respaldado por la propiedad privada y la ganancia particular; así, los haberes se tornan más autónomos: cada uno cuenta con la expectativa de que sus derechos se respeten, obviando que sus miembros frecuenten el asesinato por complacencia personal. La delincuencia se explaya por el capitalismo antisocial, característico de la ideología marxista-leninista. Para Cejas Sánchez (Rodríguez Manzanera 1981 335), ese indicador mencionado se muestra como consecuencia de la confrontación de clases heterogéneas y sus austeras representaciones disímiles; verbigracia, la explotación, la corrupción, las frustraciones personales y las injusticias. Por ende, al anular estas distinciones, concluye notablemente el proceder criminal. Raúl Carnevali (2007 24) plantea que los delitos se ocasionan por la instrucción inconsciente de los comportamientos de personas específicas, que no son tolerables para la ciudadanía en general, ya que transgreden la ética y los reglamentos jurídicos. No obstante, un modo de reducir esas discrepancias es mediante el mejoramiento de los principios de protección, que terminan siendo más importantes que el castigo que se efectúa en torno a un acto criminal; por esa razón, tendrá que abarcarse inicialmente una sistematización de las estrategias de cuidado frente al delito, como el riesgo que desencadena en la sociedad cada infractor de la ley, que está integrado en un campo de poder (Bourdieu 1997 50), pues se manifiesta en un espacio de relaciones de voluntad y monetización, donde existe la dinámica del dominante-dominado. Por otra parte, una alternativa no se basa en retirar al delincuente de los demás, sin otorgarle la facilidad a la nación de que evidencie la regulación de su prototipo o su diagnóstico sobre su conducta en lo sucesivo. Se replantearían las condicionantes sociales; peculiarmente, en los habituales mecanismos de seguridad. Al ubicar las zonas emergentes, se demuestra la posible detección de lugares en los que podrían suscitarse delitos, para que luego se vaya reconociendo e indagando de forma adecuada, tal como lo propone Michel Foucault (1979a 66-67). Ante esto, el Estado averiguaría la manera de generar su autodeterminación, con filiaciones renovadas y modos distintos de seguridad (Del Rosal 2009 29): semejante a lo que postula Foucault en su libro Vigilar y castigar (1975) al aludir a la noción de panóptico, aplicada a los presos, porque debería realizarse un rastreo perseverante en torno al comportamiento que adoptan los malhechores, con el objetivo de asegurar que, al resocializarse, estén aptos para convivir moralmente con los ciudadanos, sin que después sean resguardados; adicionalmente, los rangos gubernamentales y la burocracia serán intocables. Normalmente, se posee la expectativa de una administración de los bienes y el desempeño honrado de los funcionarios públicos con mucha eficacia y responsabilidad; sin embargo, este criterio es siempre cuestionable. 
5. Instrucción especializada en torno al Derecho. Si una persona no conoce bien sus principios legales, no se opondrá a las irrupciones de los ámbitos político y social. Con respecto a las normas jurídicas, se halla la "ley de saturación criminal", postulada por Enrico Ferri (Rodríguez Manzanera 1981 341), que articula una política criminológica. En esta, sostiene que el delito es un fenómeno social que se exhibe constantemente; por lo tanto, se exterioriza la incompetencia de las penalidades que se ejecutan, a causa de que el transgresor, aunque sabe cuáles son los principios que administran a las personas, igual violenta la ley. Como una alternativa para este percance, Ferri incorpora la ley de los "substitutivos penales", distinguida por indagar los espacios de desenvolvimiento del infractor al formular soluciones adecuadas, con el propósito de administrar un sector de las propiedades de lo delictivo (en especial, las relacionadas con la sociedad) y orientar de manera imprecisa, mas con eficiencia, sobre la dinámica criminal. Los substitutivos penales se evidencian en cuatro modalidades. La primera se aprecia por medio de la economía, que contaría con una organización garantizada por patrones heterogéneos, los cuales se identifican por el libre cambio, la independencia en migrar, la reducción de montos aduaneros, los impuestos, la industrialización del alcohol, el reemplazo del billete por la moneda, la fundación de organismos de crédito, la mejoría en el transporte, la supresión de áreas peligrosas, la estructuración cooperativa y la consolidación de un seguro social. Estos aspectos que respaldan la adecuación del capital son singularidades que intentan prevenir los crímenes provocados, principalmente, por la injusticia. El segundo substitutivo penal se patentiza mediante el orden político. Su objetivo es prevenir atentados de índoles políticos, administrativos, sociales y bélicos. Según Enrico Ferri, el rol de la Policía revelaría una incapacidad para contrarrestar problemas vinculados con el Estado y la construcción utópica de la nación. Las vías que sí son infalibles son las reformas políticas; además de la consideración de la descentralización burocrática y el referéndum. Esto se constituirá si predomina la libertad de expresión y la seguridad de que se cumplan los derechos fundamentales de las personas. El tercer orden es inherente a las ciencias, tal como lo destaca Rodríguez Manzanera (1981 342). Con esta conexión renovadora y constantemente actualizada, se adopta la idea de que es útil al producir que se propaguen variantes desconocidas para efectuar el crimen; pese a que, simultáneamente, tendrá que representarse de modo directo la contraparte: las alternativas para menoscabar las deficiencias. El cuarto substitutivo penal se detecta legislativa y administrativamente. Su asimilación es parcial, ya que comúnmente no es aceptado por las personas, según su conformación ininteligible o su rigidez: la divulgación exorbitante de normas jurídicas remite a la falta de creencia por los principios en torno a las infracciones; por ende, perdurará la transgresión a las normas por ignorancia. 
Jean Tarde (Rodríguez Manzanera 1981 347) postula una ley adicional: la de imitación, basada en que lo científico pretende asegurar la continuidad y la frecuencia de los sucesos, puesto que de esa manera se reconoce el funcionamiento habitual de una determinada sociedad. Los ciudadanos admitirán el hecho de querer adquirir un bien o una conducta en especial si este es necesario y, más aún, si se asocia con las actualizaciones modernas que les ofrece la globalización: querrán conseguirlo, aunque posean pocos medios. Obsérvese que las personas se imitan entre ellas, aun en las características: esto posibilita, además, que la identidad de cada una sea un elemento indispensable en el instante de cometer una falta (la personalidad de un individuo es afín a su delito peculiar); desde allí, se compromete con sus acciones. A su vez, Tarde (Rodríguez Manzanera 1981 350) confirma que se puede localizar al responsable de un acontecimiento ilícito si al compararse con el grupo social al que pertenece se hallan disconformidades en su composición interna; en otras palabras, si la persona no actúa de acuerdo con parámetros establecidos en la práctica de una buena convivencia en una colectividad asignada.

Aparte, una estrategia provechosa es la de concientizar en torno a los conceptos propios de la Penología, al igual que sus nexos, a causa de que se dedica a la investigación de la productividad de las coerciones, como también los logros obtenidos de las medidas de prevención. Esta disciplina brinda documentación importante a la política criminológica, para mejorar el Estado en formas efectivas para el control social, según la ocasión.

\section{La participación de los organismos del orden}

Mayormente, los Estados tienen como respaldo el empleo de la violencia. Para ello, militares y policías recurren al maltrato corporal para resguardar que la sociedad no practique estas acciones informales. Con su participación particular, se pretende el amparo de las leyes que rigen la posesión y el uso de armas, tal como lo plantean Jorge Restrepo y Katherine Aguirre (2010 280); porque el país que se representa en la novela de Gabriel García Márquez expone a personajes que no han pasado por una vida digna y meritoria de elogios, a la vez que cuentan con una armamentística que los ayuda en situaciones imprevisibles.

Si las leyes son eficaces, se asume el dominio de los encargados de maniobrar los objetos armamentísticos; asimismo, se castiga al ciudadano que transgreda las normas, ya que los militares adoptan el rol de denominarse entidades que incentivan la difusión de las relaciones de poder y producen un ambiente de paz en la sociedad. El contexto de Colombia de fines del siglo XX equivale a una etapa de reconfiguración personal de la acepción de confianza hacia los organismos armados, puesto que la función de ellos es 
otorgar un perfil autorizado para la práctica de la violencia; por otro lado, colaboran en el proceso de erigir una nacionalidad y demostrar valores para la permanencia de un Estado. Al respecto, en Noticia de un secuestro (1996), se vincula el rol de estos efectivos con la idea de que su aportación es propicia. Necesitan procedimientos que alcancen esa acción, como el espionaje, la ubicación de la zona del crimen, su mediación y la liberación. Para ejemplificar, muestro la intervención que realizan para hacer justicia con quienes provocan atentados terroristas:

La verdad era que el país estaba condenado dentro de un círculo infernal. Por un lado, los Extraditables se negaban a entregarse o a moderar la violencia, porque la policía no les daba tregua. Escobar había denunciado por todos los medios que la policía entraba a cualquier hora a las comunas de Medellín, agarraba diez menores al azar, y los fusilaba sin más averiguaciones en cantinas y potreros. Suponían a ojo que la mayoría estaba al servicio de Pablo Escobar, o eran sus partidarios, o iban a serlo en cualquier momento por la razón o por la fuerza (García Márquez 1996 152-153).

En otra oportunidad, se recurren a métodos más complejos, como identificar la proveniencia de una comunicación no presencial: el 2 de diciembre de 1993 a las 3:15 p. m. en Los Olivos de Medellín. En ese instante, matarán al representante de los Extraditables por haber establecido un diálogo telefónico con su progenitor (García Márquez 1996 333-334).

\section{Negociación deliberada con los Extraditables}

Se realizará por el Gobierno de Colombia con los narcoterroristas. Se distingue por recopilar capital de otra inversión nacional, para adecuarse a los requerimientos de los subversivos. Para emprender ese pacto en la novela, se contactaron con personas que sirvieron como canal para efectuar la confrontación; de esta manera, son posibles el diálogo y los convenios consolidados entre ellos: se responsabilizó de ese rol a los Notables (García Márquez 1996 113). Por el contrario, su funcionamiento se obstaculizó por las exigencias de los Extraditables. Por esa razón, deberán adaptarse a sus necesidades, tal como se evidencia en una situación de diálogo establecida entre Maruja y su secuestrador:

La comunicación fue inmediata y de una fluidez sorprendente. Ella empezó por preguntarle sin resentimientos qué quería Escobar, cómo iba la negociación, qué posibilidades había de que se entregara pronto. Él le explicó sin reticencias que nada sería fácil sin las garantías suficientes para la seguridad de Pablo Escobar y la de su familia y su gente (García Márquez 1996 261). 
Los requisitos expuestos son imprescindibles para erigir un pacto: la exclusividad hacia el valor que depositan los criminales al capital. De no ser de ese modo, no resultará factible. En una parte de Noticia de un secuestro, se demuestra ese anhelo monetario:

Dos años después, Escobar buscaba un segundo aire a través de la Asamblea Constituyente, varios de cuyos miembros fueron presionados por distintos medios, desde ofertas de dinero en rama hasta intimidaciones graves.

Pero también los enemigos de Escobar se atravesaron en sus propósitos. Ése fue el origen de un llamado narcovídeo, que causó un escándalo tan ruidoso como estéril. Se suponía filmado con una cámara oculta en el cuarto de un hotel, en el momento en que un miembro de la Asamblea Constituyente recibía dinero en efectivo de un supuesto abogado de Escobar. [...] Meses después, un jefe de milicias privadas que se desmovilizó ante la justicia contó que su gente había hecho aquella burda telenovela para usarla como prueba de que Escobar estaba sobornando constituyentes y que, por consiguiente, el indulto o la no extradición estarían viciados (García Márquez 1996 273-274).

Al atentar así contra los principios básicos de los ciudadanos, se propicia el surgimiento de otras variantes, como ocurre con la delincuencia, que se acrecienta mientras existen menos recursos para las poblaciones paupérrimas. Verbigracia, en Noticia de un secuestro (1996), es notoria la confrontación de los políticos con los Extraditables; mediante esta, prevalecerá la corrupción en ese ámbito; en otras palabras, los policías y los periodistas deberán negociar con los subversivos para llegar a un acuerdo. Al cotejar de esta manera al antagonista, se indaga sobre lo particular y lo indispensable de las normas de Colombia (la aplicación adecuada de la moral y lo legal), ya que estas intromisiones no suscitan un entorno de igualdad e idealización para las vidas de quienes constituyen el Estado nación, a causa de que se valoran más los prototipos erróneos y se profundiza en el conocimiento de las múltiples manifestaciones criminales. Por ejemplo, el 5 de septiembre de 1990 se aprueba el Decreto de Estado de Sitio 2047 (García Márquez 1996 88); con este, se asume una adaptación permisible para los miembros del Cartel de Medellín que se sometan a la Justicia, puesto que se les reducirá su sentencia exponencialmente si facilitan datos importantes para la investigación narcoterrorista. Este tratado se hizo para complacer, parcialmente, las necesidades del líder del Cartel de Cali; no obstante, a través del Decreto 303 (1991), el Extraditable adecuará algunas normas: prioriza la conformación de los centros penitenciarios, valida la autonomía, se preocupa por la seguridad del Gobierno, exige una menor cantidad posible de efectivos policiales dentro de la cárcel; finalmente, solicita tener conocimiento de la libertad y la certidumbre con las que contarán la mayoría de los presos. Esto conllevaría continuar desempeñando su cargo administrativo con respecto a la comercialización ilícita de drogas y pactos desde su local reclusorio. La Catedral fue un centro penitenciario que poseía muchas preferencias exclusivas; en ese lugar, Pablo Escobar decide que lo recluyan. Después, se contactará con Villamizar en una zona específica de Medellín, 
para que luego sea transportado a una prisión privilegiada. Por otra parte, quería exiliar y quitar de su función a los policías con quienes se relacionó, como los generales Miguel Maza Márquez y Miguel Gómez Padilla, además del comandante Octavio Vargas Silva: personajes que aparecen en Noticia de un secuestro (1996).

\section{La eficacia de la sanción, vista por Michel Foucault}

Al referirse a la prisión, se asume la idea de impedir la libertad de un delincuente que, por el veredicto de un juicio o un proceso penal, debe estar recluido. Según Michel Foucault (2003 46), este accionar sancionador es un modo de ejecutar la venganza por su desempeño individual o colectivo, que depende de la Justicia. Si este tipo de castigo es expuesto públicamente, genera que las otras personas entiendan el riesgo que un malhechor provoca y recapaciten en torno a su desempeño moral. Adicionalmente, consiste en la opción final que tomarían para evitar una fechoría. Sobre ello, Bernardo del Rosal Blasco (2009) plantea lo siguiente:

Las estrategias de control del riesgo tienen, por lo tanto, una finalidad incapacitante y suelen adoptar, típicamente, dos modalidades: la restricción de movimientos (encarcelamiento o vigilancia electrónica) y los mecanismos psicotrópicos, como las drogas de control del comportamiento. Por más que esta última estrategia, obviamente, plantea numerosos problemas éticos y prácticos, lo cierto es que es la única que puede ofrecer, a un preocupado "consumidor", una promesa de eliminación completa del riesgo. [...] la estrategia de control del riesgo, en la medida en que elimina la oportunidad de acción, elimina el riesgo: es evidente que si encarcelamos al delincuente de por vida nunca va a volver a cometer delitos, al menos, fuera de la prisión (31).

Con respecto a las estrategias utilizadas para reducir estas acciones y estos comportamientos criminales, Michel Foucault (2003 171) destaca el rol óptimo que se suscitan de estos; verbigracia, al recurrir al método jerárquico, constituido por el reconocimiento general de las personas que operan en ese espacio (la predominancia de un juez, luego la de los policías, los abogados, los ciudadanos y, últimamente, los prisioneros), el reo acepta las condiciones de que él es un sujeto que debe ser inspeccionado. De manera semejante, al aplicar el castigo, no se están transgrediendo sus valores como persona; es más, sirve para saber a profundidad sobre su personalidad y detectar qué sanciones son más infalibles para él. Enseguida, Foucault (2003 217) añade que eso es factible si el preso es alejado en absoluto, con el objetivo de educarlo y vigilarlo persistente e individualmente; así, empezará a desempeñarse lucrativamente. Por lo tanto, su recuperación se desarrolla siempre y cuando no interactúe con criminales; caso contrario, su forma de ser se irrumpe con todas aquellas personas que son catalogados míseramente: la interrelación con otros delincuentes provocará una riesgosa adecuación a conductas delictivas permanentes y se instruirá en modos más 
originales para cometer crímenes. Al usarse esta medida coercitiva que busca la articulación de la disciplina en un preso para una reinserción ética (resocialización), existe un respaldo que se enfoca en incentivar el surgimiento de un Estado nación con una designación óptima para quienes emprenderán cargos vinculados con el poder.

Posteriormente, para Foucault, cualquier tipo de sanción que se aplique con intereses disciplinarios conlleva una modificación absoluta en la persona; en ese sentido, resulta eficaz su inclusión. Entre los métodos para una reinserción efectiva en una colectividad, desde un centro penitenciario, se asimila un régimen de restablecimiento, que se caracteriza por la bonificación que se otorga al reo por su buen desempeño, en vez de la supresión del comportamiento basado en el castigo. Después de instruirse al prisionero bajo esa modalidad y proyectarse su liberación, él deberá rescatar sus derechos fundamentales como persona que integra un Estado nación, ya que, al ser sancionado, es factible que por inercia se obvie adecuadamente el desenvolvimiento de las relaciones humanas; por esa razón, se prevalecerá esa peculiaridad, al igual que no tendrá que percibirse como un reo, acostumbrado por sus vivencias criminales remotas a recibir violencia y castigos.

\section{Conclusiones}

La novela de Gabriel García Márquez permite detectar la conformación del Estado colombiano en sus múltiples representaciones (judicial, político, policial, militar, etc.), las mismas que no son determinantes por la práctica de una buena ética, además de frustrar las expectativas democráticas y de desarrollo que poseen los ciudadanos. Aparte, se identifican a aquellas personas que aprovechan ese momento de malestar político para ocasionar chantajes económicos y legales (los integrantes del Cartel de Cali solicitan una variación que los favorece jurídicamente). Al respecto, asumiendo que una sociedad se distingue por su organización errónea, la articulación de una política criminológica es ideal para el inicio de la construcción y el establecimiento de su propio Estado nación, que es reconocible a través de cinco etapas. La primera se efectúa por la necesidad de hallar el origen del poder que rige a los ciudadanos. La segunda se constituye por la inclusión de la noción de democracia en la sociedad, para que la percepción que adoptan de lo macrocriminal y sus consecuencias destructivas se vaya resemantizando y contrarrestando. La tercera se consolida por la configuración de una política basada en la utilización de una técnica especializada que facilite la comprensión de las áreas de la educación, las artes y la cultura para su buen desenvolvimiento y su difusión. La cuarta se respalda del aseguramiento de la secuencialidad y el mejoramiento de los mecanismos que protegen a la colectividad. Para terminar, se considera la concepción de que la sociedad tendría que adquirir una postura orientada a 
la inclusión de saberes políticos y legales. Por otra parte, se fundamentó que los militares apreciados en Noticia de un secuestro (1996) recreaban una crítica en torno a su productividad - se evidencia por el requerimiento de intercambiar bienes con los narcoterroristas o los Extraditables - ; sin embargo, mediante la política criminológica, se muestra la solución de reformular aquellos elementos que no posibilite la buena instrucción dirigida al reo. Esto es notorio con programas de concientización sobre estrategias de prevención y resocialización como recursos para corregir y disciplinar a los prisioneros.

\section{Bibliografía}

Arroyave, Liliam y Guerrero, Andrea. “Estudio de siete casos de personas condenadas por delitos contra la administración pública en Colombia, entre el 2009 y el 2010, desde la perspectiva criminológica". Criminalidad 52/2 (2010): 77-97.

Bourdieu, Pierre. Razones prácticas. Sobre la teoría de la acción. Trad. Thomas Kauf. Barcelona: Editorial Anagrama, 1997.

Calvo, José. "La intimidad en el espejo de los media. Una mirada desde la literatura y el derecho". Derecho Comparado de la Información 8 (2006): 97-136.

Carnevali, Raúl. "El multiculturalismo: un desafío para el Derecho Penal moderno". Política Criminal 3 (2007): 1-28.

Del Rosal, Bernardo. “¿Hacia el Derecho Penal de la postmodernidad?”. Revista Electrónica de Ciencia Penal y Criminología (RECPC). Recuperado de http://criminet.ugr.es/recpc/11/recpc11-08.pdf, 2009.

Foucault, Michel. La arqueología del saber. Trad. Aurelio Garzón del Camino. México D. F.: Siglo Veintiuno Editores, 1979a.

Foucault, Michel. Microfísica del poder. Trads. Julia Varela y Fernando Álvarez-Uría. Madrid: Las Ediciones de La Piqueta, 1979b.

Foucault, Michel. Vigilar y castigar. Nacimiento de la prisión. Trad. Aurelio Garzón del Camino. Buenos Aires: Siglo Veintiuno Editores, 2003.

García Márquez, Gabriel. Noticia de un secuestro. Bogotá: Editorial Norma, 1996. 
Norza, Ervyn y Espino-Duque, Gloria. “Resultados operacionales de la Policía Nacional, 2010". Criminalidad 53/1 (2011): 151-163.

Norza, Ervyn, González, Andrea, Moscoso, Manuel y González, Juan. “Descripción de la criminalidad femenina en Colombia: factores de riesgo y motivación criminal". Criminalidad 54/1 (2012): 339-357.

Restrepo, Jorge y Aguirre, Katherine. "El control de armas como estrategia de reducción de la violencia en Colombia: pertinencia, estado y desafíos". Criminalidad 52/1 (2010): 265-284.

Rodríguez Manzanera, Luis. Criminología. México D. F.: Editorial Porrúa, 1981.

Roszak, Theodore. El nacimiento de una contracultura. Reflexiones sobre la sociedad tecnocrática y su oposición juvenil. Trad. Ángel Abad. Barcelona: Editorial Kairós, 1981.

Szurmuk, Mónica y Mckee, Robert (Coords.). Diccionario de Estudios Culturales Latinoamericanos. México, D. F.: Instituto Mora y Siglo Veintiuno Editores, 2009. 